\title{
Evaluation of Atomic Layer Deposition Coating as Gas Barrier against Hydrogen Gas and Humidity
}

\author{
Damoon Sohrabi Baba Heidary*, Clive A. Randall \\ Center for Dielectrics and Piezoelectrics, Materials Research Institute, the Pennsylvania State University, \\ University Park, Pennsylvania 16802, USA
}

Corresponding Author: Damoon Sohrabi Baba Heidary

(917) 376-7737, dus255@psu.edu

\begin{abstract}
The effectiveness of $\mathrm{HfO}_{2}$ Atomic Layer Deposition coatings has been studied on $\mathrm{ZnO}$ varistors by I-V tests, impedance spectroscopy, and highly accelerated life test. Based on impedance spectroscopy analyses, the proton diffusion coefficient was measured to be $400 \mathrm{k}$ times less in the coating. Transmission electron microscopy analysis shows that the Atomic Layer Deposition films are continuous and conformal. After exposure to high temperature, partial crystallization was detected in the coating and increase proton diffusion coefficient by 150 times.
\end{abstract}

Keywords: Atomic layer deposition; gas barrier; hydrogen degradation; varistor; diffusion

Varistors or variable resistors are passive components, which are used in protection against voltage surges, that shunt the excess charge to ground [1-4]. The design is typically around ceramic materials based on $\mathrm{ZnO}$ with dopants and sintering aids added to control the nature of the controlled breakdown process and minimize the leakage in the stand-by operational condition [4] [5]. The grain size and the grain boundary compositions are critical and are back-to-back Schottky barriers controlling these conditions $[6,7][1,3]$. There is a concern about the packaging of varistor components at the atmosphere in which they are exposed to humidity or hydrogen gas[8]. The source of hydrogen gas could, for example, 
be the out-gassing of corrosive atmospheres from incompletely cured epoxies and or electrolytic capacitor seal failure [9][10][11].

There have been earlier studies on the atmosphere sensitivity to varistors, such as the work of Sonder et al.[12] who have studied systematically the effects of reducing atmosphere on the resistivity degradation of $\mathrm{ZnO}$ varistors. In their case, a reductive agent of $\mathrm{CO}$ and different percentage of oxygen and inert gas at the interval temperature of 150 to $800^{\circ} \mathrm{C}$ were considered. It was found that $\mathrm{ZnO}$ varistors can be degraded by annealing at $260^{\circ} \mathrm{C}$ in a $\mathrm{CO} / \mathrm{CO}_{2}$ atmosphere, and showing resistance can decrease from $10^{10}$ to $10^{4} \Omega$ after 33 hours of exposure to $\mathrm{CO} / \mathrm{CO}_{2}$. In addition, there are additional reports of resistivity degradation of $\mathrm{ZnO}$ varistors due to hydrogen gas exposure $[11,13]$. It will be shown in this report that the leakage current can increase from $10^{-8}$ to $10^{-4} \mathrm{~A}$ at $170^{\circ} \mathrm{C}$ after one hour exposure to a hydrogen gas.

ALD (Atomic Layer Deposition) coatings demonstrate a good gas barrier property [14-17] on the various substrates, which makes them promising to hinder the degradation process. In this letter, the effect of exposure of $\mathrm{ZnO}$ varistors to forming gas ( $4 \%$ hydrogen and $96 \%$ nitrogen) and humidity has been studied, and the application of ALD coating as a gas barrier layer has been evaluated. In addition, the proton diffusion coefficient has been measured for both $\mathrm{ZnO}$ varistor and $\mathrm{HfO}_{2}$ ALD layers to demonstrate effectiveness as gas and humidity barriers for $\mathrm{ZnO}$ based varistors.

A commercial $\mathrm{ZnO}$ varistor was cut to $15 \times 15 \times 1.4 \mathrm{~mm}$ and ground up to 1200 grit sandpaper, then a circular Pt electrode with area of $5 \mathrm{~mm}^{2}$ was sputtered to the center of both sides of the samples. The impedance spectroscopy was applied, by SR-830-DSP Lock-in connected to a charge measurement system (the test was conducted in Material Characterization Lab of Pennsylvania State University), to trace the degradation in grain and grain boundaries at 135,155 , and $175^{\circ} \mathrm{C}$, when they were exposed to forming gas (4\% hydrogen and $96 \%$ nitrogen) for 3 hours. 
$\mathrm{HfO}_{2}$ ALD coating was applied around the devices by using $150 \mathrm{LE}$, The Kurt J. Lesker Co. and the precursor of TDMAH, tetrakis (dimethylamino) hafnium (IV) $\left(\mathrm{C}_{8} \mathrm{H}_{24} \mathrm{~N}_{4} \mathrm{Hf}\right.$ ), and water. The dose times of the precursor and water were 0.15 and $0.03 \mathrm{~s}$, followed by the purge time of 10 seconds at the temperature of $200^{\circ} \mathrm{C}$ and the pressure of 400 mtorr. The growth rate was measured $1.3 \dot{A} /$ cycle.

Another set of tests was leakage current measurement to monitor the amount of resistivity degradation. The varistors with different coating thicknesses were exposed to forming gas in the interval temperature of 80 to $290^{\circ} \mathrm{C}$; for every $20^{\circ} \mathrm{C}$ increment, they were held for 30 minutes, while the leakage current was measured every second under applied voltage of 5V. A Highly Accelerated Life Test (HALT) was executed by Temperature Humidity Chamber (Blue M, Illinois, USA) at the temperature of $90^{\circ} \mathrm{C}$ and humidity of $85 \%$ for 120 hours, under $100 \mathrm{~V}$ applied voltage on the coated and uncoated samples. TEM samples were obtained by FEI Helios NanoLab 660 FIB/FESEM. The TEM analysis was executed by JEOL 2010F.

Impedance spectroscopy analysis is an effective method to monitor the relative changes in resistivity and capacitance in grain and grain boundary microstructures. We represent the impedance data $\left(Z^{\prime}, Z^{\prime \prime}\right)$ in the complex plane in the form of Nyquist or Cole-Cole plots, noting the changes with the experimental variable of different exposure times in Figure 1(a). It was found that the Cole-Cole plots can be fitted well with the two impedance element equivalent circuit shown in Figure 1(b), the electrode contribution is negligible in the $\mathrm{ZnO}$ varistor, and the largest contribution comes from grain boundary barriers. Our approach is consistent and builds on the analysis of Andres-Verges and West [18], where the grain impedance can be approximated with a pair of ideal capacitor and resistor. The capacitor is the representative of the transient charge storage in grains and the resistor the bulk resistivity of $\mathrm{ZnO}$ crystals. For the grain boundary circuit representation, another element, CPE (constant phase element[19]), is added to consider the inhomogeneity over all the grain boundaries [20]. 
The resistance of grains and grain boundaries under different hydrogen gas exposure times is shown in Figure 1 (c). The resistance of the grain boundaries at the beginning of the exposure is 100 times higher than the resistance of grains at the end of exposure. While the GB resistance decreases an order of magnitude, the grain resistance is essentially invariant under the gas exposure conditions used here. The change in GB resistance can be related to proton concentration acting as a donor dopant reducing the interfacial grain boundary resistance [11].

The change in GB resistance can be used to determine the diffusion of hydrogen into the grain boundaries, by defining appropriate boundary conditions and solving Fick's law, one can estimate diffusion coefficient of protons at $135^{\circ} \mathrm{C}$ in grain boundaries[21]. One of the boundary conditions can be concluded from the fact that the entering rate of total hydrogen ions $\left(\frac{d N(t)}{d t}\right)$ to the device is proportional to the concentration difference between atmosphere $\left(C_{0}\right)$ and surface $\left(C_{S}\right)$, which can be represented as:

$$
\frac{d N(t)}{d t}=\alpha\left(C_{0}-C_{S}\right)
$$

where $\alpha$ is a proportionality constant.

The other boundary conditions are obtained based on the assumption that the diffusion system is semiinfinite. Here, we need to consider an additional assumption, which is that the Pt electrode is not a barrier against proton diffusion. Regarding the hydrogen diffusion coefficient in $\mathrm{Pt}[22,23]$ and $\mathrm{ZnO}[11,24-26]$, the diffusion coefficient in Pt is several orders of magnitude higher than the diffusion coefficient in $\mathrm{ZnO}$ in the temperature interval of the present work. So the above mentioned assumption is valid.

The same impedance spectroscopy tests were executed at 155 and $175^{\circ} \mathrm{C}$, and the calculated diffusion coefficients are shown in Figure 1 (d). One can find the best line that passes those three points, and find the activation enthalpy for proton diffusion, as $0.88 \mathrm{eV}$, which is fairly close to the reported values of 
$1.21[25]$ and $0.91 \mathrm{eV}$ [11] for proton diffusion in ZnO. However, it is reported as $0.17 \mathrm{eV}$ [24] elsewhere. Nickel [26] has thoroughly studied the proton diffusion coefficient in single and polycrystal ZnO thin films. He argued that the activation enthalpy can depend on temperature and reported $0.75 \mathrm{eV}$ for $\mathrm{ZnO}$ poly crystals at $155^{\circ} \mathrm{C}$. It should be noted that the resultant diffusion coefficients in the present paper are for the grain boundaries of $\mathrm{ZnO}$ ceramics, which was doped with $\mathrm{Bi}$ and $\mathrm{Sb}$. See the supplementary information for SEM micrograph.

We also considered the changes to leakage current of varistors (coated and uncoated) after exposure to forming gas, which are presented in Figure 2(a). The uncoated samples were tested in forming gas and air as indicators of maximum and minimum degradation and shown as "Hydrogen" and "Air". It is observed that the leakage of all the coated varistors is as good as that of their performance in ambient air conditions up to $\sim 250^{\circ} \mathrm{C}$. It means that the ALD coatings can fully protect varistors against forming gas up to a critical temperature, no matter how thick they are. The other observation is that the critical temperature is $140^{\circ} \mathrm{C}$ for the uncoated varistor, and it can increase to $250^{\circ} \mathrm{C}$ by applying of $10 \mathrm{~nm}$ of $\mathrm{HfO}_{2}$ ALD coating.

We also considered the stability of a varistor under humidity testing and also the effectiveness of ALD coatings; some data is shown in Figure 2 (b). We see that the ALD layers can fully protect the varistors during the Highly Accelerated Lifetime Time (HALT) test, but the leakage current increases three times in the uncoated varistor at the end of the test. As water vapor is incorporated to ZnO ceramics by following reaction, the final product is hydroxide.

$$
\mathrm{H}_{2} \mathrm{O}(g)+\mathrm{V}_{O}^{*}+\mathrm{O}_{O}^{x} \rightarrow 2[\mathrm{OH}]_{O}
$$

We therefore see that both hydrogen and humidity lead to a similar final product, and there is an excess of donors to be incorporated in the grain boundaries, which lowers the insulation resistance, which degrades the varistor performance. 
To investigate the failure of ALD coating after $250^{\circ} \mathrm{C}$, TEM analysis was executed on ALD layer before and after exposing to high temperature. The TEM micrographs are shown in Figure 3. The ALD layer is continuous, flawless, and amorphous before exposing to high temperature, see Figure 3 (a) and (b). On the other hand, the ALD layer, after exposing to high temperature, is not flawless and shows Moiré fringes in TEM micrographs, as presented in Figure 3 (c). The fringes are the sign of two crystalized planes that translate or/and rotate against each other [27]. So the ALD layers are crystallized and cannot stop hydrogen as effectively as before crystallization. If the ALD layers had not become crystallized, they could have protected the varistors for a long time, with the maximum protection as demonstrated in the HALT test; there is no leakage increase even after 120 hours exposure at $90^{\circ} \mathrm{C}$.

The true barrier power of $\mathrm{HfO}_{2}$ can be seen through Figure 1 (d) and Figure 2. Figure 1 (d) shows that the proton diffusion coefficient is $400 \mathrm{k}$ times higher in $\mathrm{ZnO}$ varistors than the ALD coating, the exposure to high temperature and partial crystallization increase the diffusion coefficient by 150 times but that is still much smaller than the diffusion coefficient in $\mathrm{ZnO}$ varistors. Obviously, the low proton diffusion coefficient is the cause of the low leakage current of coated samples in Figure 2. As shown in TEM micrographs, the ALD coating is conformal and continues with very low diffusion coefficient and can offer an effective gas barrier, even though its thickness is in the range of nanometer.

In the cases of both humidity and hydrogen gas exposure, the ALD coatings provide adequate protection and offer an effective solution to future packaging of passive components in circuits that operate under extreme environments.

\section{Acknowledgements}

This material is based upon work supported by the National Science Foundation, as part of the Center for Dielectrics and Piezoelectrics under Grant No. IIP-1361503 and 1361571. 
References

[1] D. Clarke, J. Am. Ceram. Soc. 502 (1999) 485.

[2] K.I. Hagemark, J. Solid State Chem. 16 (1976) 293.

[3] T. Gupta, W. Carlson, J. Mater. Sci. 20 (1985) 3487.

[4] J. Han, P.Q. Mantas, a. M.R. Senos, J. Eur. Ceram. Soc. 22 (2002) 49.

[5] K. Magnusson, S. Wiklund, J. Appl. Phys. 76 (1994) 7405.

[6] F. Greuter, Solid State Ionics 75 (1995) 67.

[7] F. Stucki, F. Greuter, Appl. Phys. Lett. 57 (1990) 446.

[8] D. Baba, SohrabiHeidary, W. Qu, C. a. Randall, J. Appl. Phys. 117 (2015) 124104.

[9] T.K. Gupta, J. Am. Cerum. Soc. ,73 (1990) 1817.

[10] J.N. Calata, J.G. Bai, X. Liu, S. Wen, G. Lu, IEEE Trans. Adv. Packag. 28 (2005) 404.

[11] D.G. Thomas, J.J. Lander, J. Chem. Phys. 25 (1956) 1136.

[12] E. Sonder, M.M. Austin, D.L. Kinser, J. Appl. Phys. 54 (1983) 3566.

[13] D. Thomas, J. Lander, J. Phys. Chem. Solids 2 (1957) 318.

[14] C.-T. Chou, P.-W. Yu, M.-H. Tseng, C.-C. Hsu, J.-J. Shyue, C.-C. Wang, F.-Y. Tsai, Adv. Mater. 25 (2013) 1750.

[15] Z. Liu, Y. Gong, W. Zhou, L. Ma, J. Yu, J.C. Idrobo, J. Jung, A.H. MacDonald, R. Vajtai, J. Lou, P.M. Ajayan, Nat. Commun. 4 (2013) 2541.

[16] J. Meyer, P. Görrn, F. Bertram, S. Hamwi, T. Winkler, H.-H. Johannes, T. Weimann, P. Hinze, T. Riedl, W. Kowalsky, Adv. Mater. 21 (2009) 1845.

[17] S.M. George, Chem. Rev. 110 (2010) 111.

[18] M. Andres-Verges, A. West, J. Electroceramics 1 (1997) 125.

[19] V.F. Lvovich, Impedance Spectroscopy: Applications to Electrochemical and Dielectric Phenomena, John Wiley \& Sons, Hoboken, 2012.

[20] E.J. Abram, D.C. Sinclair, a. R. West, J. Electroceramics 10 (2003) 165. 
[21] D. Sohrabi Baba Heidary, C. a Randall, Acta Mater. x (2015) xx.

[22] J. Cermak, A. Kufudakis, G. Gardavska, 63 (1979).

[23] Y. Ebisuzaki, J. Chem. Phys. 49 (1968) 3329.

[24] K. Ip, M.E. Overberg, Y.W. Heo, D.P. Norton, S.J. Pearton, C.E. Stutz, S.O. Kucheyev, C. Jagadish, J.S. Williams, B. Luo, F. Ren, D.C. Look, J.M. Zavada, Solid. State. Electron. 47 (2003) 2255.

[25] E. Mollwo, ZEITSCHRIFT FUR Phys. 138 (1954) 478.

[26] N. Nickel, Phys. Rev. B 73 (2006) 195204.

[27] D.B. Williams, C.B. Carter., Transmission Electron Microscopy: A Textbook for Materials Science, Springer, New York, 2009.

Figure 1

Figure 2

Figure 3 

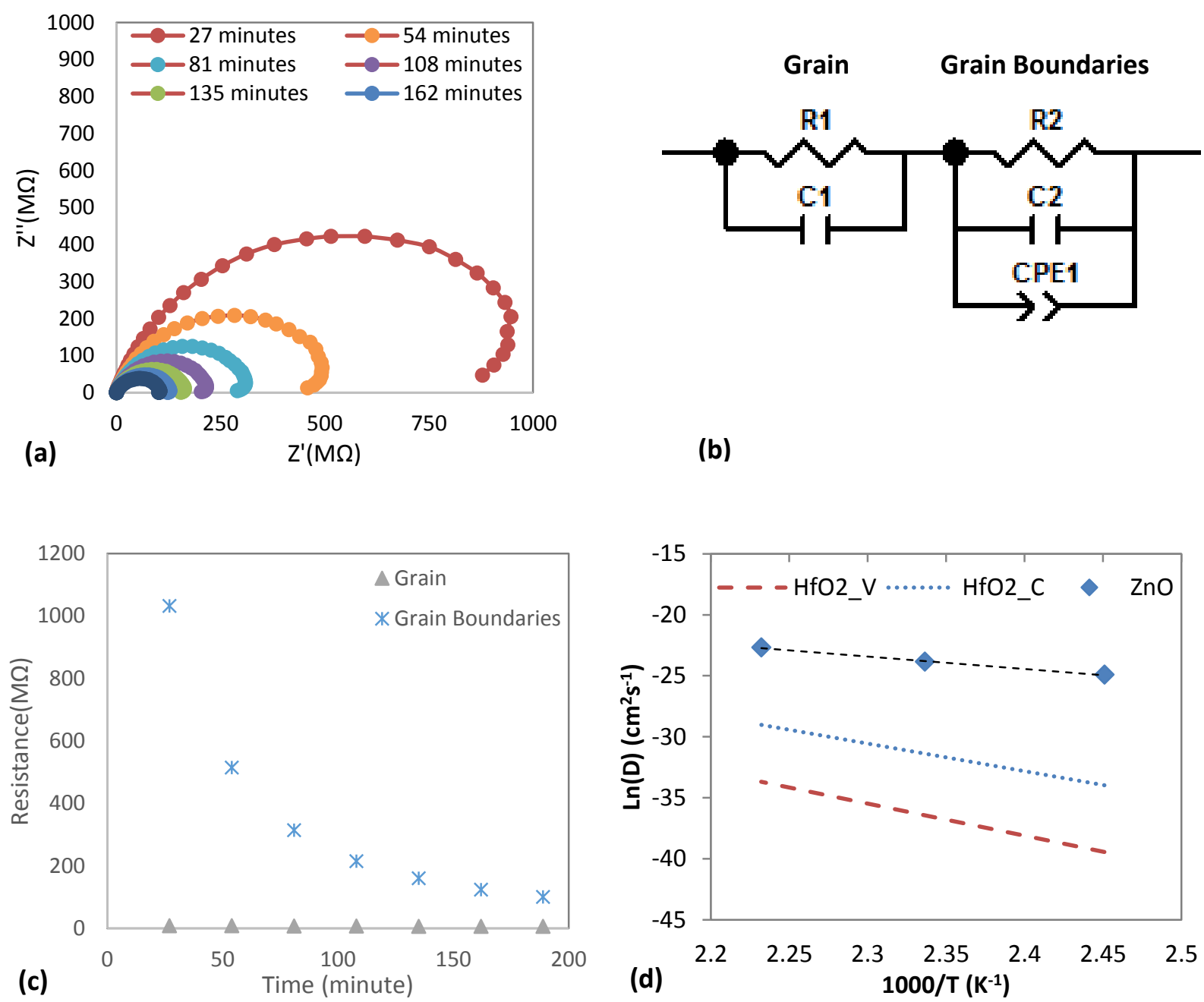

Figure 1 (a) Cole-Cole plots for ZnO varistor exposed to forming gas at $135^{\circ} \mathrm{C}$ at different exposure time; (b) Equivalent circuit; (c) Resistance of grains and grain boundaries vs. gas exposure time at $135^{\circ} \mathrm{C}$; (d) Proton diffusion coefficients vs. reciprocal temperature in the grain boundaries of $\mathrm{ZnO}$ varistors, virgin $\mathrm{HfO}_{2} \mathrm{ALD}$ layers and crystalized $\mathrm{HfO}_{2} \mathrm{ALD}$ layers. 

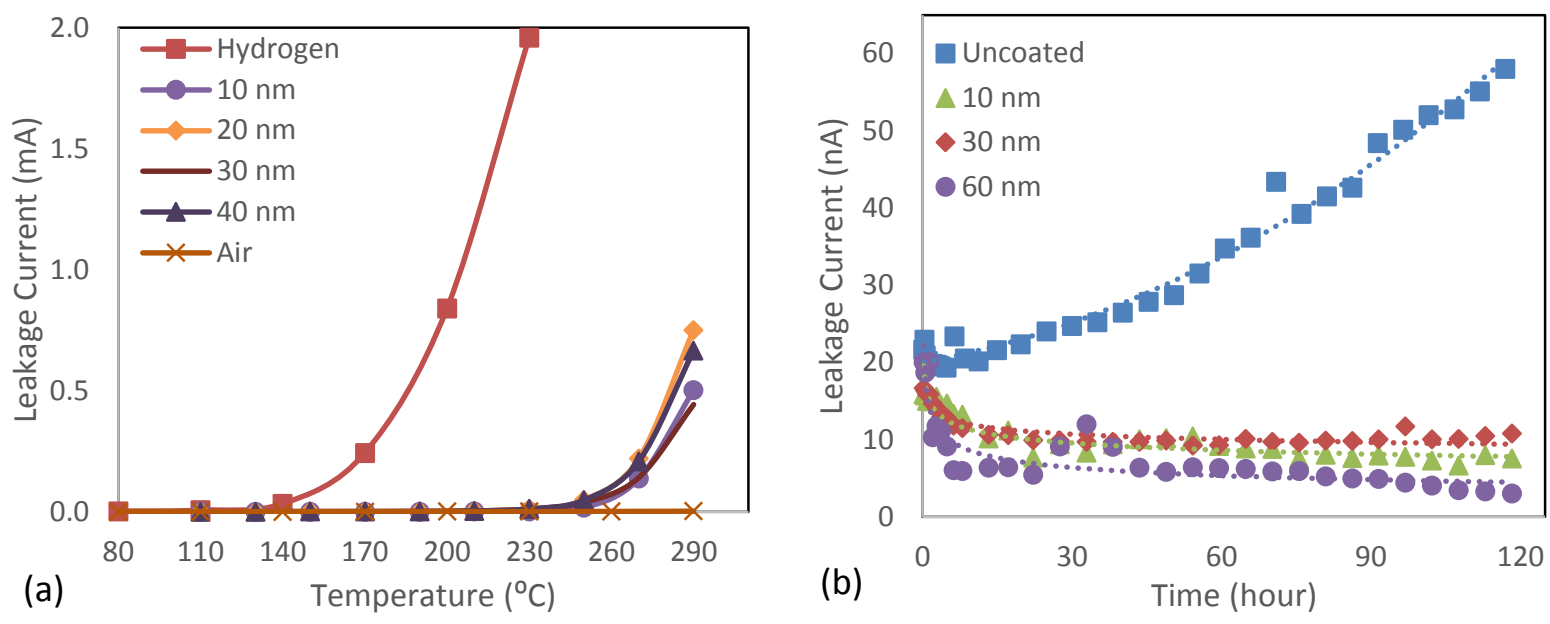

Figure 2 (a) Leakage current vs. temperature for $\mathrm{ZnO}$ varistors coated with various thickness of $\mathrm{HfO}_{2}$ ALD at forming gas and $5 \mathrm{~V}$ applied voltage; the Air and Hydrogen curves are representative of minimum and maximum degradation. (b) Leakage current vs exposure time for uncoated and coated varistors with different thickness of ALD layers at temperature of $90^{\circ} \mathrm{C}$, humidity of $85 \%$, and under $100 \mathrm{~V}$ applied voltage. 

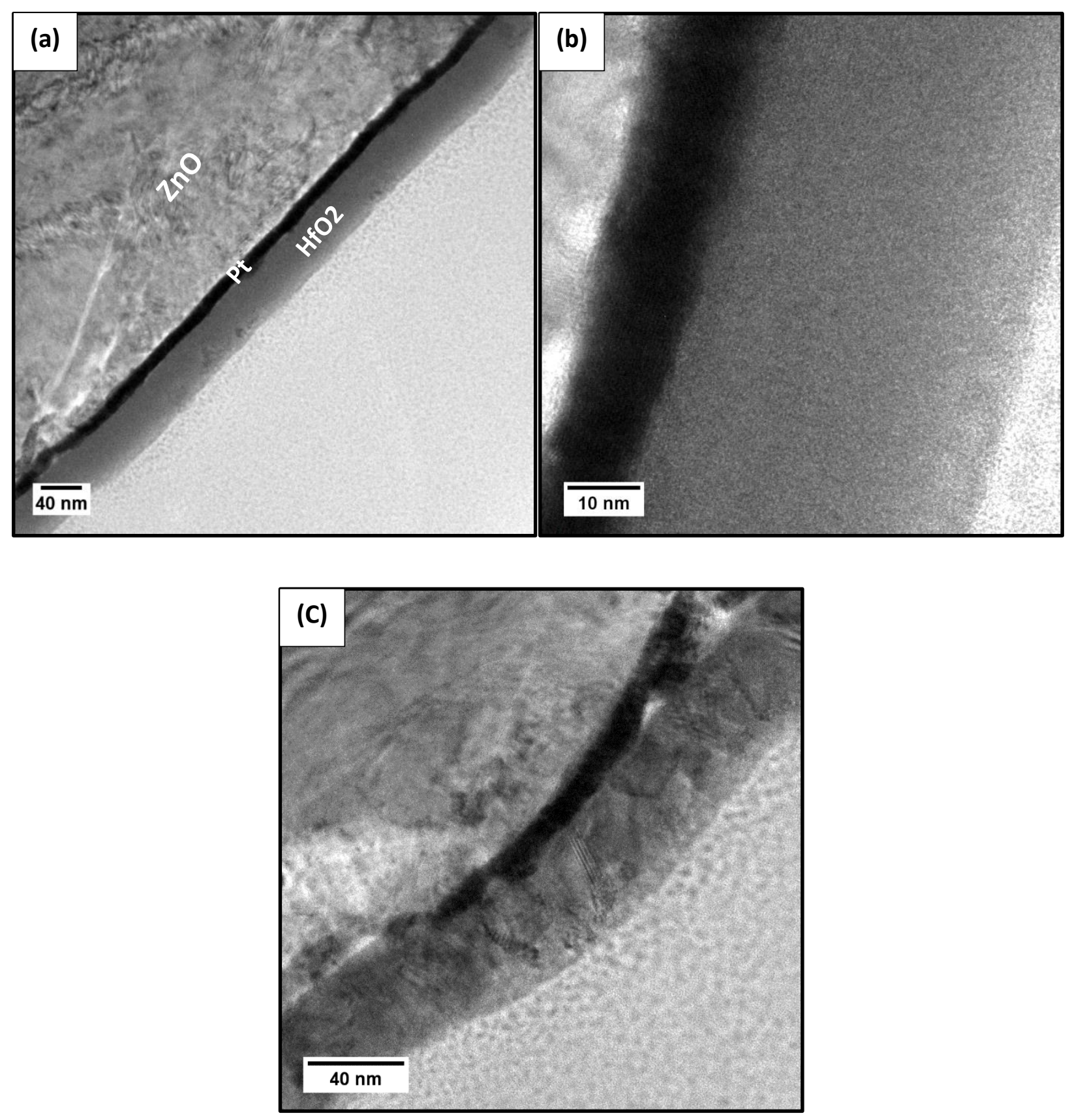

Figure 3 TEM micrographs of $\mathrm{HfO}_{2}$ ALD layer with thickness of $40 \mathrm{~nm}$ on $\mathrm{ZnO}$ varistors (a), (b) before, and (c) after exposing to $290^{\circ} \mathrm{C}$ 